\title{
Theoretical Design Science in Human-Computer Interaction: A Practical Concern?
}

\author{
Steven R. Haynes \& John M. Carroll, The Pennsylvania State University, University Park, PA, USA
}

\begin{abstract}
Design research, without empirical evaluation, is often looked upon as a poor relation to more obviously experimental work. A common reason to reject design studies submitted for publication concerns their failure to provide an empirical evaluation of the use and effects of an artifact in the laboratory or in more realistic field settings. The authors argue that this scepticism towards pure theoretical design research without empirical results not only hinders scientific progress and scientific efficiency in human-computer interaction research, but also discounts the value of designs conceived and realized in practice. Pure theoretical design research has value because envisioning and implementing a design is a form of theorizing, theory integration, theory refinement, and analytic evaluation. The artifact, in essence, embodies a theory, with analytical value independent of its empirical evaluation. The activities of analysis, design, and construction are common in both academe and in design practice, and represent an underexploited resource for systems design science. In part this limitation might stem from the lack of epistemological grounding for design as a knowledge generating activity, and in part from the lack of a distinct methodological perspective from which to assess theoretical design science. The authors ground their perspective with reference to the philosophy of science and through analysis of a design research exemplar, and suggest a set of criteria for evaluating research products in theoretical design science.
\end{abstract}

Keywords: design practice, design theory, philosophy of science, theoretical research

Intellectuals trust the intellect, but not the senses, empiricists the senses but not the intellect. (Imre Lakatos, For and Against Method)

Research programs in human-computer interaction (HCl) often include both designs and built artifacts among their phenomena of interest, and as independent or dependent variables in empirical studies. Humancomputer interaction is concerned with how people (and groups, organizations, and other social systems) can make effective use of information technology, along with the psychological, social, and technical factors that either impede or enhance users' experience with technology. Research in $\mathrm{HCl}$ is complex just because it goes beyond understanding and predicting phenomena along one dimension, such as the psychological, and attempts instead to explain phenomena at the intersection of at least two dimensions, such as the psychological and the technical. Often, the number of dimensions increases, as in cases where understanding effective use is a function of psychological, technical, organizational, and cultural causes.

Partly because $\mathrm{HCl}$ has grown out of the psychological disciplines, the field is grounded methodologically in empirical approaches to science and in an appreciation of experimental methods as the sine qua non of valid $\mathrm{HCl}$ research (Gray \& Salzman, 1998). Though many other methods are admitted, including surveys and questionnaires, ethnography, and usage log analysis, they are typically held to standards of validity recognizably derived from the classical scientific method, especially the experimental method. This puts design research at a distinct disadvantage, especially design research that does not include empirical evaluation of the artifacts that result from what is often an intensely intellectual and knowledge-generating activity. The problem might be especially acute for design-as-practiced and for the artifacts that result. Produced outside the veil of scientific legitimacy, such artifacts and the knowledge they carry lack a recognized epistemological status. In other words, there is little appreciation in academic research for knowledge gained from methods that are not empirical. This limitation in research activity stems partly from the belief that these "unorthodox efforts", to the academician's eye, are without methodological rigor.

This paper is an argument for the legitimacy of design - in particular, theoretical design research - as a first-class form of inquiry in both the science and practice of human computer interaction research. Design in this case refers to activities and artifacts used to analyze and creatively envision a new artifact or artifact feature. Research refers to the various forms of rigorously structured methodical inquiry directed at increasing our understanding of the world. By theoretical design research we mean the intersection of these two activities up to, but not including, evaluation of 
an implemented design. The principled and creative envisioning and construction of the artifact is, we argue, a form of theory-building. It is theory-building because theoretical design research involves analyzing existing theories, existing designs, and prior empirical results as the basis for new designs grounded in that previous work. These activities may be carried out in the lab or in industrial and other practical settings. In any case, the products of theoretical design research are artifacts that embody conjectures, explanations, and predictions useful to science not only as theoretical integrations, but also as instruments and directions for later empirical evaluation.

There is a growing interest in explaining and developing the current epistemological boundaries of information technology and information systems design. The National Science Foundation, for example, recently initiated a program on The Science of Design dedicated to just this cause. Further, conferences and workshops across technology design disciplines are increasingly visible, including the First International Conference on Design Science Research in Information Systems and Technology (DESRIST), the workshop on Exploring Design as a Research Activity (EDRA) at DIS 2006, and the CSCW and Design workshop at ACM CSCW 2006. Though these forums are as much about empirical design research as anything else, they also hint at the need for a better understanding of the essence(s) of design - as activity, artifact, and as knowledge - and as a prominent component of an articulated and broadly accepted research practice.

Our particular aim here is to develop a better understanding of design as a form of theorizing, because we believe this understanding will not only aid progress in human computer interaction research, but will also help us better understand the research value of designs that are conceived and realized in practice. The concept of design-as-theory is not new. We will discuss some of the many conceptions of that idea later, and it might be the case that the structure and content of the concept is recognized and accepted implicitly across disciplines where design activity and artifacts are evident in research. If so, we hope to begin to expose some of the assumptions underlying the role that design in research practice can play - for theory-building especially, but also as independent variable, dependent variable, instrument, apparatus, or perhaps something else - so that we and others can assess whether we are making the best use of the knowledge embedded in and derived from the creation and use of complex artifacts. Tied to that concern is the question of whether or not $\mathrm{HCl}$ design research, as currently practiced, makes the best use of the human and economic resources available to it. Specifically, we want to know if the special talents of theorists, methodologists, and engineers are being leveraged most effectively with regard to the deepest and most enduring questions challenging the field.
From the start we should say that our conception of the value of theories is pragmatic. Independent of their correspondence with truth and reality, theories contribute to inquiry by articulating previously unrecognized avenues for research. Theorists do this by fusing empirical results with conjectures concerning the relation between the two. Together, they form systems for describing and predicting how new technologies will behave and perform in their intended domain. The potential that we claim is embedded in theories demands that researchers develop criteria to help us decide which new theories should be taken seriously and investigated using costly empirical studies. Such criteria will help answer questions concerning the value of a single designed artifact, in particular, of an interactive system conceived either explicitly or implicitly as a proposition or hypothesis about how positive change might result by introducing new technology.

Evaluation criteria are important because they provide a community with a common framework or vocabulary for talking about and assessing research contributions. If, as has been argued, every scientific theory put forth so far has proven to be false (Kukla, 2001), the problem narrows to identifying which ones have the best potential for being true, for providing explanations, and contributing to human understanding, and for being useful as predictive tools. The balance of this paper focuses on situating the activities, artifacts, and knowledge that result from $\mathrm{HCl}$ design research squarely within the tradition of scientific theory-building.

\section{WHAT ARE THEORIES?}

The philosopher of science Rudolf Carnap (1966) described theories as constructed from prior empirical results and laws, and employed as a means for suggesting and directing new empirical research. This ability to suggest new avenues for empirical research is one of the major roles of theory in science, along with explaining how prior empirical results fit together, and predicting results of empirical studies yet to be carried out. A theory organizes and orients potentially disparate empirical results into a general framework. Kukla (2001) similarly defines theories in science as a collection of interrelated laws, where at least one of the laws is theoretical. A theory is a proposition that goes beyond the data, but still uses empirical data as the basis for informed conjectures about unobservable causal mechanisms.

Articulating a precise definition of theory requires taking one of at least two stands on the nature and validity of knowledge. On one hand, realists claim that our perceptual apparatus only allows us to obtain some subset of the world and we rely on inference for the rest. The terms and relations so inferenced are our theories. Instrumentalists, on the other hand, claim that theories are just statements we make to serve some convenient 
purpose. Theoretical entities and relations in the instrumentalist tradition might be known or suspected to be false, yet still provide a useful framework for understanding and using prior empirical results. These theories help us understand gaps in existing knowledge and propose predictions and other actions we could take if we fill those gaps with theoretical terms. Some go so far as to claim that instrumentalist theories exist only to motivate empirical research in a particular area (Kukla, 2001).

Carnap (1966) argues that identifying valid grounds for the discovery of theories and theoretical laws using empirical foundations is one of the major problems facing scientific methodology. If theories are derived from prior empirical results and conjectures about possible relationships between them, one then wonders how these conjectures are derived.

Some of the rules governing theory construction are relatively simple. New theories should not contradict existing data. Others are more tricky. For example, researchers must decide how best to satisfy the causal gaps in empirical results, with the intention of constructing a more general account of the phenomena of interest. This satisfying involves stretching the power of existing data in order to imagine and envision, to theorize that is, the causal and structural relationships that bind the data into a coherent, cohesive explanation. In the process, as Kukla (2001) describes it, "theorizing trades off a certain amount of epistemic security for an increase in the breadth of one's knowledge" (Kukla, 2001, p. 75). Theories that are too narrow lack explanatory power and are subject to being subsumed under later, more general ones. Too general, and a theory fails to provide any real insight into its phenomena of interest, or to allow for falsification as proposed by Popper (1968).

Researchers and philosophers of science adhering to the inductivist, or observational, stance suggest that theories emerge from attempts to identify patterns in data (Kukla, 2001). These patterns are not vertical generalizations, which would be empirical laws rather than theory, but evidence supporting hypothesized horizontal relations among data sets, in other words, the transfer of empirical results in one relatively narrow domain to another, with an analytic rationale (i.e. a justified theory) for why the transfer might be useful. An example discussed later is the transfer and integration of the mouse, menus, icons, and the desktop metaphor to create a new design theory of direct manipulation interfaces (Card, 1996).

Pierce (1954a) first proposed the use of abduction for the generation of new scientific theories and hypotheses. Abduction is a form of "inference to the best explanation" (Harman, 1965, p. 88), where the existence of entities or events is explained by the best fit to the available evidence. Fit in this sense includes consideration of evidential coherence, the plausibility of proposed causal mechanisms, and consistency with other things we know about the world. Especially problematic in abduction are estimates of the relevance of particular data to the event being explained. How data are marshalled and used to justify an abductive conclusion (a particular theory) is considered to be a creative, subjective process not amenable to logical analysis.

According to Kukla (2001), there are no rules for adducing theory from data sets, no rules for determining the prior probabilities of theories, and no rules for measuring the scope of a theory. This lack of analytic rules or guidelines at the front end of theory construction presents challenges to later attempts at analytic, post hoc theory assessment. That the process of theorizing seems so mysterious is at odds with traditional conceptions of science as a highly rational, rule and protocol-driven enterprise. However, this conception has been challenged before by Latour (1987), Feyerabend (1993), and Kuhn (1970), among others, who claim that theory-building is far more opportunistic, ad hoc, and chaotic than is commonly understood under conventional views of science.

Theory assessment and theory choice are among the most problematic topics engaging philosophers of science, and the scientific establishment itself. Though considerable effort has been directed at understanding theory choice at the macro or research program level (Kuhn, 1970; Lakatos et al., 1999; Popper, 1968), less work has been directed at development of criteria for assessment of a priori theories, specifically those without a significant base of related empirical results upon which to analyze their confirmational status. Such criteria are necessary if we are to understand how best to evaluate new designs-as-theories that have been proposed for empirical investigation.

Among the criteria that have been proposed for a priori theory assessment are consilience (Thagard, 1978), simplicity (Kukla, 2001), and predictive and explanatory power (Hempel, 1965). These criteria are heuristics, or guiding principles to help establish the worth of a theory before it has been put to empirical test. Each is controversial, in the sense that the philosophers of science who act as arbiters of theory choice often disagree on their relative merits. Each of them, however, contributes by providing metrics we can use to help determine a theory's face validity.

Consilience is a measure of how much a theory explains relative to competing theories (Thagard, 1978). A theory that is more consilient is one that is able to integrate and cover the greater number of different classes or categories of evidence. Kukla (2001) refers to this criterion as a theory's scope. Ultimately, fewer theories with greater explanatory power focus empirical 
investigations on a limited number of concepts, thereby efficiently leveraging data gathering efforts. This criterion, though, trades off against the classic, Popperian (1968) ideal of theory falsifiability. The more general a theory and the more facts it explains the less likely it is to make the bold, falsifiable predictions that qualify it for true scientific status.

Simplicity as a criterion for theory assessment refers not only to simplicity in the number of terms required to express the theory, but also to the level of difficulty in computing predictions and explanations of the phenomena referred to by the theory's terms. The simplicity criterion has an almost mystical quality about it, with philosophers often grounding justifications for the criterion in statements about nature's inherent simplicity (though this itself is a controversial claim). In practice simplicity is also a common criterion for assessment of designs, for example, in the principle known as Occam's Razor. However, Kukla (2001) questions the utility and appropriateness of the simplicity criterion, arguing instead that "the essential virtue of a theory is to answer a lot of questions correctly" (p. 79), rather than to be simple.

The function of science is to explain and predict. Theories are among the most powerful tools for contributing to our understanding of the world, and to our ability to predict and therefore control certain aspects of it. According to Popper (1968), a theory's quality is a function not just of its ability to predict, but also of its ability to suggest accurate but counterintuitive predictions. At the same time, a theory should help reduce complex and unobservable phenomena to mechanisms that can be more easily explained. In this way theories serve as a lens that, through simplification, abstraction, and analogies to the familiar (Thagard, 1978), help illuminate causal and other mechanisms at work in the world.

\section{THEORETICAL DESIGN SCIENCE}

Design research has been characterized as design with a primary focus on obtaining knowledge, rather than creation of a product for commercial or other use (Zimmerman et al., 2007). As with research in more traditional forms of science, such as physics or biology, design research in human-computer interaction often entails integration of prior empirical and theoretical work (Fallman, 2003). These designs organize prior research into an artifact-as-hypothesis, predicting new or improved technology-mediated performance of some human activity. At the same time that a design is a theory, its implementation (the artifact) is an instrument for conducting research on the theory. The process of creation becomes the means for thinking and talking about how prior knowledge might be harnessed for creation of a new artifact.
Simon (1996) in his now-classic The Sciences of the Artificial, argues that designed artifacts consist of an inner and outer environment and claims that a sort of harmony between these two is the key to a design's success and value. The inner environment describes the structure of the artifact while the outer describes the environment in which the artifact is intended for use. However, these concepts partly ignore, at least with regard to the value of a given artifact, the process of creation - the analysis, design, and building that identified and integrated the most salient aspects of the inner and outer environments. In the creation of modern, complex systems designs, these activities involve background research, reasoning and problem-solving, and reflection. They integrate and generate knowledge of the best ways to support human activity in the domain of interest. The process of finding this harmony between the inner and outer environments is where design knowledge is created and given its first test by the analytic envisioning of its creators.

Framing design activity as research sets it apart from design in (some) industries and (some) arts. Design for research goes beyond producing a solution. Instead, it moves toward some identified problem to investigate, identify, and finally communicate why a particular design serves to improve the situation in the problem domain. Design researchers and those who incorporate significant design work in otherwise purely scientific research programs are, however, considered to be relatively unreflective about design methodology as an integral part of their research strategy (Reich, 1994). Antonsson (1987), for example, observes that design researchers typically do not justify their research in the classical, hypothetico-deductive paradigm of the scientific method, because design is still considered a creative process by designers, even in research contexts. Further, the process by which design hypotheses are synthesized is often, like scientific theories, not well explained or understood.

Theories are not, according to most conceptions of the philosophy of science and the scientific method, just "happy thoughts that have occurred to their authors" (Pierce, 1954b, p. 315). Theories are systems of propositions about the structure, behaviour, and relations of postulated entities that are used to predict and explain things about the world. Theorizing is a means for progressive science; new theories are often a response to problems identified in current modes of thinking (Dillon, 1995). New theories build on the work of others and integrate disparate theoretical positions and empirical results to suggest new avenues for inquiry. Design-as-theorizing, however, requires that the propositional content inscribed into a design be made explicit as design rationale, for example, or in the scholarly papers that explain and justify the form that a design takes. 
Common assumptions governing our understanding of the relationship between science and technology include the idea that science is concerned with theoretical knowledge, while technology is concerned with applied knowledge. Further, theoretical knowledge is necessarily prior to applied knowledge. Pitt (2000) argues that technological theorizing requires that we examine the methods through which information supporting the rationale for the theory was obtained. So far, in $\mathrm{HCl}$, while there has been work on conceptualizing and articulating design as a form of theorizing, relatively little work has explored the grounds for justifying and evaluating designs as bona fide theories, or as embodied propositions that could lead to theories. In the rest of this section, we explore some efforts to describe technology designs as technological theories. In the section following, we lay out a set of criteria for evaluating such theories, and then show them applied to one influential $\mathrm{HCl}$ research program.

\section{PROGRAMMING AS THEORY-BUILDING}

In an early and famous paper Naur (1985) described programming as a form of theorybuilding, theory development, and, importantly, theory maintenance. To Naur, the goal of programming is to gain insight into some problem domain and to develop a theory of how best to address or mitigate the problem. In his view, programming was inclusive especially of the design activity that precedes code production. This activity includes knowledge collection, aggregating, and synthesizing, which, in the social context of software development, is significantly challenged by the need to preserve and rationally extend this knowledge as a design evolves over time and at the hands of successive design teams.

Naur was especially concerned with the loss of fidelity that occurs in the time and space between the original developers of a program and their problem and solution theories, and those tasked with enhancing and maintaining the program code later. Through case study analyses, he shows how developers of extensions to an original design often failed to obtain or comprehend the full depth of understanding brought to bear by the original program designers. Without communication between the two groups, later designers would fail to efficiently build upon aspects of the original design that were not only sound, but most effective relative to the problem-solution mapping. This mapping, in Naur's view, is found in the design rationale, a justification for a design decision that captures the reasoning, design rules, quantitative estimates, trade-offs between alternatives, and other information supporting the decision.

That this concern was considered so important in production software engineering suggests that research designers and programmers should take this entropy even more seriously as a threat to theoretical coherence over time. Naur was concerned that the original core design rationale, the foundational theory mapping a domain problem and domain concerns to a design solution, was lost as original designers-theorists moved on and new ones took their place and constructed their own incomplete and inaccurate understanding of the design. Program code and supporting documentation were found insufficient to support this knowledge transfer.

Preserving and communicating design rationale from one programming increment to another is essential to truth preservation both in systems development as practiced, and in design science. Designs embed a particular understanding of both the problem domain and the solution approach. Technology designs have been referred to as "frozen organizational and policy discourse" (Bowker \& Leigh Star, 2000, p. 137) and as "society made durable" (Latour, 1991, p. 103), expressing the idea that designs are repositories of knowledge, albeit ones in which the knowledge is made invisible and largely inaccessible (Brooks, 1987) to those who would seek to leverage this knowledge in later design endeavours.

Naur's notion of theory followed closely that of Ryle (1963) in describing a theory as knowledge of how to do something, such as construct a program, or design a human computer interface component using explanations, justifications, and answers to questions, about the activity to be supported. Applied to the practice of programming, this notion of theory echoes Schön's (1983) reflective practitioner, who applies knowledge in doing by engaging in both reflectionin-action and reflection-on-action as means to more intelligently incorporate one's own knowledge, and the knowledge of others, in order to generate new, reusable knowledge from lessons learned in practice.

Naur's position on programming as theorybuilding points to the critical role that designed artifacts and design rationale play as carriers of knowledge. This knowledge is, however, fragile and requires that those who create it also take the time to justify their knowledge so as to support progressive theorizing over time. This focus on documenting and reflecting on rationale is another aspect of scholarly design that differentiates it from industry practice.

\section{DESIGNS AS THEORIES}

The idea of designs and artifacts as theories is not new and has previously been considered by the ACM ComputerHuman Interaction (CHI) community. Carroll (1990), for example, identified human tasks and designed artifacts as two of the key scientific objects central to what was then considered the applied psychology of human-computer interaction. Carroll and Kellogg (1989) 
argued for the role of designs and artifacts as embodying theoretical terms and constructs. Dillon (1995) showed how the activities and processes of science and design share many core attributes including their concern with problem-solving and the role of theoretical conjectures as vehicles for progress.

More recent work in the $\mathrm{CHI}$ community has continued to develop these ideas. Several have pointed out the important role of designs and artifacts as incorporating and making material the integration of theories and other knowledge from disparate disciplines and research streams (Fallman, 2003; Zimmerman et al., 2007). The way in which these elements are arranged in a design demonstrates a particular stance or perspective towards some problematic aspect of a human activity and how best to support it with new technologies. The artifact or design specification plays a crucial role in making this integration apparent and communicable between individuals, groups, and communities.

One observes that design theorizing crosscuts the usual distinctions made about design as research, for example, as clinical, applied, or (rarely) basic research (Buchanan, 2001). Any time a design specification is created or a new artifact is built, this theorizing is a necessary part of the analytic, synthetic, creative, and communicative activities that define design. Though very little is known about analytic, synthetic, and creative activities, they have been characterized as involving, among other cognitive acts, a back and forth process of imagination and judgment (Nelson \& Stolterman, 2003), or envisioning and evaluating (MacLean \& McKerlie, 1995). In this iterative process, a design proposal is generated, extended, and assessed with concern for the purpose the artifact is meant to serve, and the constraints and other criteria that bound what is possible in a given context.

Cross (1999) names design epistemology as one of three core elements of design research, the other two being design praxiology, focusing on design practice and process, and design phenomenology, the study of artifacts themselves. Cross claims that the activities of modelling and synthesis are central to design epistemology, which in design research are conducted with the express purpose of acquiring new knowledge methodically, informed by research and design that has gone on before, and with the intent to communicate the knowledge gained for use and assessment by others. One goal of such a science of design is "the establishment of appropriate structures for the design process" (Cross, 2001, p. 53), which, in our view, includes structuring design as a form of scientific theorizing.

Dewey's (1966) model of inquiry provides an important link from a problem domain, to the thinking involved in finding a solution, and the learning that takes place as a result. Dewey argued that all inquiry and learning is, as with design, motivated by some problem. Active engagement with the problem space, making rather than discovering or understanding a given solution, is central to this mode of thinking, research, work, and learning. In the same way, creation of a design and artifact to address some problem or requirement is itself a form of inquiry, quite apart from the knowledge generation that might result from an evaluation of the results of this generative inquiry.

Here we attempt to further the view of designs and artifacts as theories by grounding this conceptualization in the philosophy of science and by providing criteria for assessment of research products from design theorizing. Our focus is on the kinds of design theorizing that explicitly or implicitly takes as its objective improving people's experience in the world, whether at work or in recreation. This differs from some design research, which we would classify as exploratory, in which artifacts are meant to evoke as-yet unknown responses from their users. This includes Dunne and Raby's (2001) writings on design as evoking critical discourse, and the work of Gaver et al. (2004) on designs as probes to facilitate entirely new thoughts, experiences, and interactions.

Theories are frameworks of empirical knowledge and theoretical conjectures brought and bound together into a system for explaining and predicting phenomena in some aspect of the world. Empirical knowledge, in this case, consists of facts about the world grounded in verified observation of some form or another such as experiments, surveys, and case studies. This knowledge can take the form of laws or other well-established universals (Hempel, 1994) or can be probabilistic (Salmon, 1993). Theories bind together, with conjectures, these laws, universals, and probabilities into a coherent system that describes and predicts some aspect of the experienced world.

One way in which designs differ from theories is in their inherently functionalist orientation. That is, they derive from problems or purposes in the world. Some requirement or requirements set suggests a need for a device or system to support human activity. The motivations for undertaking design theories are therefore at the same time both much more heterogeneous and much narrower than purely scientific theories.

Designs are theories in that they either explicitly or implicitly (usually the latter) hypothesize that an envisioned artifact will improve human performance or perceptions on some tool-supported activity. What is important to design research and the science of design is that the reasons, or rationale, for holding these hypotheses be made explicit. In this paper we hold that the breadth and quality of these reasons are among 
the most important criteria for assessing the quality of theoretical design research.

Science consists of various forms of inquiry directed at increasing our understanding of the world. These forms are generally structured and methodical, and are carried out with respect for some appropriate set of evaluation criteria. Design Science is inquiry into and evaluation of design activities, representations, and artifacts in order to understand the effect of the context in which design occurs and designs are created, and the effect of designed artifacts on the context in which they are used.

Heider (1958) argued that all people in essence are naive scientists, forming theories and testing them against actions and experience. Often these theories are implicit, unstated conjectures about the state of the world, coupled with different ways to go about living within it. As highlighted by Naur (1985), implicit theorizing and implicit rationale are the enemies of quality programs, and, by extension, quality design theorizing.

Popper (1968) argued that science proceeds through a cycle of conjectures and refutations. There are, obviously, two sides to the activity of science: the making of conjectures, and the attempts to refute them. His influential criterion for differentiating between science and pseudo-science calls for construction of bold, daring conjectures as the basis of scientific progress. In addition to empirical tests he allowed for critical analyses as a fully qualified attempt at disconfirmation. As with other philosophers and sociologists of science he argued that bold conjectures, even if false, were essential to the fertility of a scientific program.

To Popper, the central role of a conjecture was that it be capable of making predictions and that the truth or accuracy of these predictions could be tested and either verified or disproven. Designs for interactive systems are inherently scientific from a Popperian perspective in that they are designed for some purpose and their ability to meet the requirements of this purpose can be assessed as having been met or made better, or else not. Designs are conjectures about how things might be better. Designs as theoretical research should provide the reasons or rationale for the predictions and explanations they provide. This research should also identify avenues for empirical work to support or refute the inscribed theory.

\section{EVALUATING THEORETICAL DESIGN SCIENCE}

If designs in $\mathrm{HCl}$ research are to be accepted as theories, and if theoretical design research is to be accepted as a first-class method for making progress in $\mathrm{HCl}$, the community needs criteria for assessing the relative merits of research products submitted for publication to journals and conferences. These criteria can also help identify design research worthy of further empirical evaluation. Some sort of a priori filtering process is needed to understand when a theory qualifies for serious attention from other researchers and from experimentalists. In this section we propose a set of criteria for just this kind of assessment. We hope that these criteria will invite discussion about the value of design theorizing and about what constitutes adequate justification for undertaking empirical studies of innovative designs.

The criteria below are derived from the philosophy of science, from theories of what constitutes a theory, and from analyses of theorizing as practiced in science. As discussed earlier, the process of deriving new theories, from both empirical results and theories that have come before is considered something of a mystery. Our intention here is not to prescribe a single inflexible assessment process, but to identify and articulate some focusing principles to be applied when evaluating the relative quality of theoretical design research. In particular, we propose that theoretical design research should exhibit seven key attributes. Theoretical design research should be: purposeful, illuminating, grounded, integrative, innovative, appropriate, and elegant. In the rest of this section each criterion is described further and justified. In the section following we provide an example of the criteria applied to an instance of theoretical design research.

Theoretical design research should be purposeful. Technology design both as an activity and as an artifact is defined by the function or purpose it is intended to serve in support of "humanity at work" (Pitt, 2000, p.11). In theoretical design research, this purpose should be clearly identified and explained with reference to a population of plausible users, their core requirements with respect to the design, the activities the artifact is meant to support, and details of the use contexts. Concrete, realistic scenarios of use (Carroll, 2000), for example, can help show how a design is intended to operate within the human ecology. A design's purpose should evoke metrics and measures for later empirical work, for example, by promising to enhance performance or reduce errors through its support of human activity.

Theoretical design research should be illuminating in the sense that it clearly identifies operationalizable constructs, research questions, and hypotheses that are subject to empirical evaluation. Theoretical conjectures emerge from analysis of the gaps in extant empirical laws and other established results. A proposed design consists of one or more hypotheses about how best to resolve such gaps. These should be clearly identified along with any ideas about the methods and procedures potentially most effective for addressing the issues. In this way, theoretical design research can make a real contribution to research programs, both by identifying 
opportunities for new research and education, and by helping to describe the boundaries of knowledge in the discipline.

Theoretical design research should be grounded, clearly describing how conjectures were derived to address the gaps between what is already known from prior work. Grounded theoretical design research identifies prior designs, theories, and empirical work in the same domain space, and shows how they informed new theoretical conjectures. In conventional published research this is accomplished through a review of related research and literature, which provides a trail of logic leading to the questions being asked in the current work. In this way even the most brilliant and insightful ideas in design research may appear as the proper result of understanding the domain and its challenges.

Theoretical design research should be integrative. Science is meant to be progressive, steadily constructing increasingly explanatory accounts to enhance our understanding of the world. Though this account of scientific practice and scientific progress has been called into question, perhaps most influentially by Kuhn (1970), it still represents an ideal that is central to both the ethos of and practice within scientific research programs (Lakatos et al., 1999; Popper, 1968). In the philosophy of science, unification is considered one of the core criteria for the evaluation of new theoretical projects (Kitcher, 1988). In today's environment of increasingly feature-rich technologies distributed across space, time, and people, theoretical design research should introduce new theories or new theoretical integrations, help to strengthen theories proposed by others in $\mathrm{HCl}$ research, fuse empirical content from diverse research programs, or act as a means for adapting and communicating theories from other fields to those working in $\mathrm{HCl}$. High-quality theoretical design research should be consistent in the manner in which components are brought together for inclusion in a single artifact.

Theoretical design research should be innovative and should make bold or risky claims and predictions, following Popper (1968), because designs that replicate or make relatively minor, incremental improvements on designs already known to work are probably best left for industrial development and production. The degree of innovation apparent in a theoretical design is a measure of the extent to which it will open new avenues for further theorizing and empirical investigation. Critical in the research context, though, is the idea that innovation must be justified with regard to some clear purpose, which is the first criterion. The criterion of purpose promises to somehow provide something that is not only different, but better than designs that have come before (Newman, 1997).
Theoretical design research should be appropriate, in other words, it should exhibit a very close mapping between a theory of the problem domain and the design theory represented in a built or specified artifact. This corresponds to Simon's (1996) notion of harmony between a design's inner and outer environments. This mapping should demonstrate face validity, which means that researchers and reviewers should be able to appreciate the extent to which the target user and stakeholder population has been taken into consideration in development of the design's core ideas. It should explain the role of contextual factors, especially environmental constraints, that were instrumental in the realization of the design (Beyer \& Holtzblatt, 1998). Theoretical design research that emerges from ethnography and other immersive fieldwork, for example, might be judged as inherently more appropriate than technological solutions dreamed up in a laboratory.

Theoretical design research should be elegant and should add value through the unification and integration of theoretical and empirical constructs previously treated as distinct. A measure of the value of a theory is the extent and coherence of this integration. In the philosophy of science, simplicity and the principle of Occam's Razor are frequently proposed as base criteria for the assessment of new theoretical perspectives (Kant et al., 1934). Both engineering practice and systems theory likewise provide arguments for the role of elegance and simplicity in meeting the various non-functional requirements often used to assess technological solutions (Pressman, 2005).

The Xerox Star as design research In this section we analyze the Xerox Star as an example of theoretical design research. Though now many of the ideas embodied in the Star are considered law-like in their applicability to human-computer interaction, at birth the Star machine and its software represented a revolutionary progression in the state of the art. We use the Star as a mechanism for better understanding the criteria outlined in the previous section, and, we hope, exhibiting the potential power of theoretical design science as a bona fide research method. Miller and Johnson (1996) provide a comprehensive overview of the Xerox Star machine as an example of successful and influential user-interface design. We draw on this work as the primary source for the analysis that follows here.

The Xerox Star was the first information processing system to fully embody the theory of direct manipulation human-computer interfaces. Direct manipulation was a design theory in that it integrated knowledge of people, both physical and psychological, with knowledge of what was achievable with the computing technology available at the time. It prescribed direct manipulation as a better alternative to command-line user interfaces, and based this prescription on both empirical and theoretical science, and on lessons learned from practice. Clearly 
the instrument or construct created to embody the theory, the Xerox Star system itself, has been refined and has evolved to incorporate new scientific knowledge and new technologies available to more effectively respond to this knowledge. Still, it is striking how visible many of the core elements of the theory are in today's most advanced personal computers.

The Star also embeds a higher-level theory about how knowledge workers want to and should interact with computers. This is the idea of the invisible computer (Johnson et al., 1989) that transparently supports people finding, creating, transforming, and communicating information. Part of the realization of this higherlevel theory was in its implementation of the directmanipulation user interface, and part in the seamless integration of the different applications theorized to support common office information management, such as document management, graphics, personal databases, and e-mail.

The Xerox Star was the product of design practice as much as it was of design research. The system was released in 1981 as an information-processing platform designed specifically for office professionals and staff. The core objective of the Star was to make the computer a transparent tool for office workers who would not be interested in, might even be frightened by, the technical mechanisms and rationale underlying the productivity enhancing tool. In this way, the Star was clearly and explicitly purposeful in terms of the target users and stakeholders and the human activities the technology was designed to support. “The idea was that professionals in a business or organization would have workstations on their desks and would use them to produce, retrieve, distribute, and organize documentation, presentations, memos, and reports" (Johnson et al., 1989, p. 11).

It can be argued plausibly that the Xerox Star illuminated the way forward for much of the research on humancomputer interaction and personal computing that has been carried out since the early 1980s. Because it was the product of one of computing's most famous research laboratories, Xerox PARC, some of these avenues were made explicit in papers and other publications, which spawned a number of streams of empirical research in user interface evaluation, the use of metaphor in interface designs, and personal information organization.

The Xerox Star was deeply grounded in prior theoretical ideas and empirical results. The theoretical ideas of Vannevar Bush (1945), Douglas Englebart (1962), and Alan Kay and Adele Goldberg (1977), among others, were incorporated into the design theory. The design was also grounded in empirical evaluations of the mouse and other alternative input devices, icon recognition, and menu selection, again among many other options. Still, the Star was theoretical in the sense that until it was invented, no single empirical evaluation had suggested that this particular integration of elements would result in the success exhibited by, if not the Star itself, which was a commercial failure, then by derivative designs such as those later produced by Apple Computer and Microsoft. It seems arguable that no empirical evaluation could have shown the validity of propositions at this scale.

Not only was the Star designed to be an integrated information-processing system for its users, it was also highly integrative in terms of the range of component technologies, empirical results, and theories it incorporated into the single, core design. In particular, the Star was designed to integrate much of the important research that had been carried out at Xerox PARC. The objective of creating an effective information management machine with much of its complexity hidden from the user was achieved by assembling diverse advanced technologies in a principled way, from a consistent command vocabulary that included the ubiquitous open, copy, and delete commands, which was theorized to reduce cognitive load to bit-mapped displays, which, it was theorized, would facilitate desktop publishing.

There is little controversy about the extent to which the Xerox Star represented an innovative leap forward for human-computer interaction. The Star introduced the graphical user interface, progressive disclosure of preferences and settings, and WYSIWYG display and printing, among others. Prior to the Star, commandline interfaces were the norm for office workers who were often required to understand in some detail the operating system and even the hardware underlying the applications they used on their computers, most of which were mainframe or mini-computers.

As one of the dominant companies in the office equipment business, Xerox was perhaps uniquely aware of the kinds of technologies and other tools appropriate to the office automation context. Despite this pedigree, Miller and Johnson (1996) point to appropriateness as one of the failings of the Star project. In their account, they take its designers to task especially for failing to provide an open, extensible architecture so that system adopters could commission development of specialized applications tailored to their needs. The subsequent success of the Star's design descendants, the Apple Macintosh and Microsoft Windows, among others, points to the extent to which the system's designers were able to theorize a success mapping between the outer environment, the office setting of the modern knowledge worker, and the inner environment, an assemblage of artifact features including the directmanipulation user interface and inherently tight application integration. 
The Star represented an elegant integration of what are now considered generic technology affordances, such as the Windows user interface coupled with a mouse pointing device, but which were at the time a leap forward in terms of the simplicity they provided to the user as an integrated solution. The WYSIWYG display and printing capability, in particular, was considered a graceful and obvious solution to the problem of input/ output synchronization.

\section{CONDUCTING THEORETICAL DESIGN RESEARCH}

We advocate design as a first-class method for conducting theoretical research, in particular, for theorizing about human phenomena and how humans are mediated by artifacts in human-computer interaction. This advocacy is motivated by our belief in the necessity of identifying methods to enable continued progress in understanding how technology can better support human activity. An example of the kind of broadmindedness we are promoting can be found in the literature of interpretive research in management information systems (MIS), where a single work (Klein \& Myers, 1999) was able to legitimize, in the mind of many sceptics, the contributions of interpretive studies to the MIS corpus. The guidelines and assessment criteria provided researchers, reviewers, and editors with a framework for use in evaluating research products, formerly mysterious to many, with more conventional training in scientific method and epistemology.

The criteria set given earlier in the paper is meant to act as focusing principles for those undertaking design as a knowledge-generating research activity. We do not propose that these criteria take on the status of prescriptions, nor do we suggest that there is any one process likely to consistently result in the "best" possible outcome of any theoretical design research program. We do suggest, however, that researchers and practitioners consider using criteria such as these to help assess the merits of a proposed design before undertaking expensive and time-consuming evaluation programs.

\section{A DIVISION OF LABOUR IN HCI DESIGN RESEARCH?}

A progressive science of $\mathrm{HCl}$ might require a division of labour between designing theorists and those more interested in and capable of the design and execution of methods for evaluating the theoretical propositions inscribed into designs. Though there are surely researchers capable and skilled in both areas, it is perhaps more likely that, as in physics, science is better served through a division of labour that has theorists producing tight, integrative conjectures for understanding and predicting while empirical researchers construct and carry out rigorous studies of these theories. Such a division of labour allows researchers to most effectively leverage their specialized talents, and perhaps create a more efficient and effective research program where an evaluative feedback loop separates empiricists from the theoreticians who propose new constructs and relations.

Nancy Cartwright (1991) argues that most great theories are made up of a higher proportion of conjectures than of statements of fact and that what gives a theory its greater explanatory power is the breadth and generality achieved through these propositions that hold together sparse and disparate empirical knowledge. Such theories come from deep knowledge of the state-of-the-art in one's field. The state-of-the-art in $\mathrm{HCl}$ is increasingly found in a multidisciplinary amalgam of theoretical and empirical work on how technology supports people working with information. Understanding the range and depth of this knowledge will, as the field matures, present significant challenges to those who aspire to create powerful theories for explaining and predicting phenomena at this intersection.

Theories, under this sort of division of labour, would come primarily from theorists, whose role it is to understand both the current and historical theories underlying a field, and the extent of their empirical support. Empiricists, on the other hand, would focus on developing and refining methods for more effective assessment of theoretical constructs. This is not to say that 'border crossing' between the theoretical and empirical realms would be in any way restricted, only that the field might benefit from more efficient organizing. Theoreticians should be allowed to focus on what they do best: provide more well-grounded and justified theoretical constructs to fuel the empirical programs in their field.

Design in a research context involves not just producing specifications, supporting documentation, and artifacts, but also providing explanations about why a particular design represents an appropriate mapping between the problem domain and the theoretical solution. Complex information system designs are never solutions per se, they are theories about what will work and why in a given context. Because of the recognized role of context in complex systems success (Beyer \& Holtzblatt, 1998), a design theory should also include the contextual factors that partially determined the solution. Designs may be idealized, but their realization is typically shaped by a broad range of constraints, such as available time, money, materials, the capabilities of the prospective users of the system, and the constraints of computing and computing/communication infrastructure.

\section{GENERAL THEORIES IN DESIGN SCIENCE}

Generality, in the form of consilience, in other words, a weaving together of knowledge from many different 
areas, is one of the foundational criteria for the evaluation of competing theories (Kukla, 2001). The possibility of general design theories in $\mathrm{HCl}$ might, however, go against some of the intuitions we have about interactive systems used in complex problem domains and organizational contexts. Flexibility and adaptability to particular users and their contexts has long been recognized as a key capability of usable systems. This leaves open the question of how to account, with a general theory, for a design that is tuned for the context in which it is intended for use. It is possible that more general designs might be relegated to the status of curiosity just because of their lack of domain and contextual specificity. It may be that there are no general designs; designs are general theories codified for a specific context - that is their virtue. The role of a science of design might therefore be to derive these generalities from the particular instances of technologies that do get built and then evaluated.

Unlike some of the more general theories that are used in human-computer interaction research, such as activity theory (Nardi, 1996), design theories are (often) less general but more precise. Though activity theory can help guide design, it does not suggest a particular artifact, nor does it make explicit claims about specific features or attributes of technology to support the human activity it helps to describe. Popper's (1968) falsifiability criterion suggests that more general theories, such as psychoanalysis, are less likely to qualify as scientific. Kukla (2001) argues simply that more general theories are less likely to be true just because of their ambition and range of application. Perhaps designs are good theories just because of their relatively limited scope. A program of theoretical design research might then take as one of its goals to establish the boundary conditions or scope of applicability for the theories-asdesigns proposed.

\section{THE PRIORITY OF DESIGN AS THEORY-BUILDING}

As Pierce (1954a) argued, before construction begins, a homebuilder has already answered hundreds of questions about the design. Some of these answers might be wrong, to be sure, but they generally possess a rationale and are representative of a valuable integration of lessons learned from prior constructions and theories about the best way to get a good house built. Similarly, in $\mathrm{HCl}$ and other areas of systems research, designers of technology in the research context are compelled to consider designs that have come before and the results from their empirical evaluation, though in practice this is often an ideal rather than a truism (Newman, 1997). Clearly though, the training we receive in the scientific method, regardless of its epistemological commitments, sensitizes us to the notion that research products should be carefully positioned within their historical paradigm and their state-ofthe- art.
Design-centred research that fails to expose its underlying theoretical terms and relations increases the difficulty of achieving a progressive science of $\mathrm{HCl}$. That this state of affairs is evident might be partly due to the fact that designs are sometimes considered secondary to the evaluations conducted to assess their effect on human performance and satisfaction. Elevating the status of $\mathrm{HCl}$ design to a form of theorizing equivalent to that carried out in other fields of inquiry might have the effect of both increasing the validity and quality of those that are proposed as the basis for scientific programs and decreasing the quantity of new tools proposed as solutions to $\mathrm{HCl}$ 's most pressing problems. Such a shift might help to focus and coordinate the efforts of the $\mathrm{HCl}$ research community.

\section{LEVERAGING THE VALUE OF DESIGN-AS- PRACTICED AS DESIGN RESEARCH}

Modern conceptions of the designer as reflective practitioner (Schön, 1983) point to some of the as-yet unexploited value in practical design as a knowledgegenerating activity. The knowledge created from design activities is, however, notoriously difficult to capture, reify, and reuse. This may be especially true for design in industry, where economic and other pressures put a premium on the tangible and immediately saleable artifacts that result from design. What is missing in these contexts is an appreciation for the value of design knowledge both as an economic good (Reich, 1995), and as the scientific outcome of intellectual activity. The latter may come only through increased professionalism in the related fields of systems design and humancomputer interaction, when communities of practice actively produce, share, and appreciate one another's contributions to progress in the field, as, for example, between physicians and medical researchers.

Some of the theoretical and methodological tools necessary to achieving this objective already exist. Kukla (2001) points out why this sharing should happen in psychology, and Vincenti (1990) notes how it already does in aeronautical engineering. Complex, interactive systems design is still an infant relative to these two fields, but not by a wide margin relative to other scientific disciplines. As in the medical sciences, practitioners in $\mathrm{HCl}$ need wellgrounded and accepted guidelines and protocols for solving recurring interaction design problems. Pattern libraries for $\mathrm{HCl}$ design have begun to provide some of these (Borchers, 2001; Tidwell, 2005). Practicing $\mathrm{HCl}$ designers still face many interaction design problems that require innovative solutions, for example, in multidimensional information visualization, which is where their talents should be focused. Researchers on the other hand need access to complex systems they can study in the context of use, so that the results they produce are relevant to practice. Treating designs as theories, with recognizable attributes and open questions understood by all, might 
provide researchers and practitioners with a type of boundary object that spurs the conversation in ways that evolve in response to progress made in both communities.

\section{CONCLUSION}

Theories inscribed into designs and artifacts are integrators and aggregators of empirical content in $\mathrm{HCl}$ research. By definition, $\mathrm{HCl}$ is the bridge between the social-psychological human, and the technological computer system. In $\mathrm{HCl}$ research, designs embody attempts to describe, explain, and predict the effect of technology on human activities in context. Designs are theories realized; they are theories couched in narratives or formalisms intended to be implemented as artifact. Like a system of equations, a design so represented forces the researcher to resolve gaps or ambiguities in the foundational theories and empirical results motivating the design effort. This is hard work, and involves empirical generalization and theoretical conjecture (innovative design) when there is no solid guidance on how to fill a particular gap or explain an ambiguity.

As human-computer interaction becomes more pervasive and as the technologies developed to support human activity become more complex, the range and depth of theoretical and empirical knowledge required to meet design requirements will become correspondingly sophisticated. We need researchers devoted to the practice of theorizing these complex designs. This theorizing requires multidisciplinary knowledge in the state of the many sciences (and arts) informing the field. Obtaining, maintaining, and applying this knowledge to the development of new theories- as-designs requires that we acknowledge and accept the role of design theorists in practice and in the academy.

\section{ACKNOWLEDGEMENTS}

The authors would like to thank the United States National Science Foundation (NSF, grant number IIS0639939) for supporting this research.

\section{REFERENCES}

Antonsson, E. K. (1987). Development and testing of hypotheses in engineering design research. ASME Journal of Mechanisms, Transmissions and Automation in Design, 109(2), 153-154.

Beyer, H., \& Holtzblatt, K. (1998). Contextual design: Defining customer-centered systems. San Francisco, CA: Morgan Kaufmann Publishers.

Borchers, J. (2001). A pattern approach to interaction design. New York: Wiley.

Bowker, G. C., \& Leigh Star, S. (2000). Sorting things out: Classification and its consequences. Cambridge, MA: MIT Press.
Brooks, F. P. (1987). No silver bullet: Essence and accidents of software engineering. IEEE Computer, 20(4), 10-19.

Buchanan, R. (2001). Design research and the new learning. Design Issues, 17(4), 3-23.

Bush, V. (1945). As we may think. Atlantic Monthly, July.

Card, S. K. (1996). Pioneers and settlers: Successful user interface design. In M. Rudisell, C. Lewis, P. B. Polson, \& T. D. McKay (Eds.), Human-computer interface design: Success stories, emerging methods, real-world context (pp. 122-169). San Francisco, CA: Morgan Kauffmann.

Carnap, R. (1966). The nature of theories. In M. Gardner (Ed.), Philosophical foundations of physics: An introduction to the philosophy of science (pp. 225-246). New York: Basic Books.

Carroll, J. M. (1990, April 15). Infinite detail and emulation in an ontologically minimized $\mathrm{HCl}$. Paper presented at the Proceedings of the SIGCHI Conference on Human Factors in Computing Systems: Empowering People, Seattle, WA.

Carroll, J. M. (2000). Making use: Scenario-based design of human-computer interactions. Cambridge, MA: MIT Press.

Carroll, J. M., \& Kellogg, W. A. (1989). Artifact as theory-nexus: Hermeneutics meets theorybased design. Proceedings of the SIGCHI Conference on Human Factors in Computing Systems: Wings For the Mind, 7-14.

Cartwright, N. (1991). The reality of causes in a world of instrumental laws. In R. Boyd, P. Gaspar, \& J. Trout (Eds.), The philosophy of science (Vol. 379386). Cambridge, MA: MIT Press.

Cross, N. (1999). Design research: A disciplined conversation. Design Issues, 15(2), 5-10.

Cross, N. (2001). Designerly ways of knowing: Design discipline versus design science. Design Issues, 17(3), 49-55.

Dewey, J. (1966). Democracy and education: An introduction to the philosophy of education (1st Free Press pbk ed.). New York: Free Press.

Dillon, A. (1995). Artifacts as theories: Convergence through user-centered design. Proceedings of the Annual Conference of the American Society for Information Science, 208-210.

Dunne, A., \& Raby, F. (2001). Design noir: The secret life of electronic object. Basel, Switzerland: Birkhäuser.

Englebart, D. C. (1962). Augmenting human intellect: A conceptual framework. Menlo Park, CA: Stanford Research Institute.

Fallman, D. (2003, April 510). Design-oriented human-computer interaction. Paper presented at the SIGCHI Conference on Human Factors in Computing Systems, Ft. Lauderdale, Florida, USA.

Feyerabend, P. (1993). Against method (3rd ed). London and New York: Verso.

Gaver, W. W., Bowers, J., Boucher, A., Gellerson, H., Pennington, S., \& Schmidt, A. (2004, April 24-29). The drift table: Designing for ludic engagement. Paper presented at the $\mathrm{CHI}$ '04 Extended Abstracts on Human Factors in Computing Systems, Vienna, Austria.

Gray, W. D., \& Salzman, M. C. (1998). Damaged merchandise? A review of experiments that compare usability evaluation methods. Human-computer Interaction, 13, 203-261. 
Harman, G. (1965). The inference to the best explanation. Philosophical Review, 74, 88-95.

Heider, F. (1958). The psychology of interpersonal relations. New York: Wiley.

Hempel, C. G. (1965). Aspects of scientific explanation. Aspects of Scientific Explanation and Other Essays. New York: Free Press.

Hempel, C. G. (1994). The function of general laws in history. In M. Martin, \& L. C. McIntyre (Eds.), Readings in the philosophy of social science (pp. 43-53). Cambridge, MA: MIT Press.

Johnson, J., Roberts, T. L., Verplank, W., Smith, D. C., Irby, C. H., \& Beard, M. (1989). The Xerox Star: A retrospective. Computer, 22(9), 11-26, 28-29.

Kant, I., Meiklejohn, J. M. D., \& Lindsay, A. D. (1934). Critique of pure reason. London: J. M. Dent \& Sons.

Kay, A., \& Goldberg, A. (1977). Personal dynamic media. IEEE Computer, 10(3), 31-41.

Kitcher, P. (1988). Explanatory unification. In J. Pitt (Ed.), Theories of explanation (pp. 167-187). New York: Oxford University Press.

Klein, H. K., \& Myers, M. D. (1999). A set of principles for conducting and evaluating interpretive field studies in information systems. MIS Quarterly, Special Issue on Intensive Research, 23(1), 67-93.

Kuhn, T. S. (1970). The structure of scientific revolutions (2nd ed). Chicago: University of Chicago Press.

Kukla, A. (2001). Methods of theoretical psychology. Cambridge, MA: MIT Press.

Lakatos, I., Feyerabend, P., \& Motterlini, M. (1999). For and against method: Including Lakatos's lectures on scientific method and the LakatosFeyerabend correspondence. Chicago: University of Chicago Press.

Latour, B. (1987). Science in action: How to follow scientists and engineers through society. Cambridge, MA: Harvard University Press.

Latour, B. (1991). Technology is society made durable. In J. Law (Ed.), A sociology of monsters: Essays on power, technology and domination (pp. 103-131). London: Routledge.

MacLean, A., \& McKerlie, D. (1995). Design space analysis and userepresentations. In J. M. Carroll (Ed.), Scenariobased design: Envisioning work and technology in system development. New York: John Wiley.

Miller, L. H., \& Johnson, J. (1996). The Xerox Star: An influential user interface design. In M. Rudisell, C. Lewis, P. B. Polson, \& T. D. McKay (Eds.), Human-computer interface design: Success stories, emerging methods, realworld context (pp. 70-100). San Francisco: Morgan Kauffmann.

Nardi, B. (Ed.). (1996). Context and consciousness: Activity theory and human-computer interaction. Cambridge, MA: MIT Press.

Naur, P. (1985). Programming as theory-building. Microprocessing and Microprogramming, 15, 253-261.

Nelson, H. G., \& Stolterman, E. (2003). The design way: Intentional change in an unpredictable world. Englewood Cliffs, NJ: Educational Technology Publications.
Newman, W. M. (1997, August 1820). Better or just different? On the benefits of designing interactive systems in terms of critical parameters. Paper presented at the Conference on Designing interactive Systems: Processes, Practices, Methods, and Techniques, Amsterdam, The Netherlands.

Pierce, C. S. (1954a). The architecture of theories. In J. Buchler (Ed.), Philosophical writings of Pierce (pp. 315-323). New York: Dover.

Pierce, C. S. (1954b). The essentials of pragmatism. In J. Buchler (Ed.), Philosophical writings of Pierce (pp. 251-268). New York: Dover.

Pitt, J. C. (2000). Thinking about technology: Foundations of the philosophy of technology. New York: Seven Bridges.

Popper, K. R. (1968). Conjectures and refutations: The growth of scientific knowledge. New York: Harper \& Row.

Pressman, R. S. (2005). Software engineering: A practitioner's approach (6th ed). Boston, MA: McGraw-Hill Higher Education.

Reich, Y. (1994). The study of design research methodology. Transactions of the ASME. Journal of Mechanical Design $117(2 A), 211-214$

Reich, Y. (1995). Measuring the value of knowledge. International Journal of Human-computer Studies, 42(1), $3-30$.

Ryle, G. (1963). The concept of mind. Harmondsworth, UK: Penguin.

Salmon, W. C. (1993). Scientific explanation and the causal structure of the world. In D. H. Ruben (Ed.), Explanation (pp. 78-112). Oxford, UK: Oxford University Press.

Schön, D. A. (1983). The reflective practitioner: How professionals think in action. New York: Basic Books.

Simon, H. A. (1996). The sciences of the artificial(3rd ed). Cambridge, MA: MIT Press.

Thagard, P. R. (1978). The best explanation: Criteria for theory choice. Journal of Philosophy, 75(2), 76-92.

Tidwell, J. (2005). Designing interfaces: Patterns for effective interaction design. Sebastpol, CA: 0'Reilly.

Vincenti, W. G. (1990). What engineers know and how they know it: Analytical studies from aeronautical history. Baltimore, MD: Johns Hopkins University Press.

Zimmerman, J., Forlizzi, J., \& Evenson, S. (2007, April 28-May 03). Research through design as a method for interaction design research in $\mathrm{HCl}$. Paper presented at the SIGCHI Conference on Human Factors in Computing Systems, San Jose, CA, USA.

\section{CORRESPONDENCE}

Steven R. Haynes,

College of Information Sciences \& Technology,

301J IST Building,

The Pennsylvania State University,

University Park, PA 16802, USA.

E-mail: shaynes@ist.psu.edu

ISSN 1749-3463 print/ ISSN 1749-3471

DOI: $10.1080 / 17493460701872016$

(C) 2007 Artifact 